\title{
DINAMIKA PERTUMBUHAN PENDUDUK DAN KUALITAS AIR DI INDONESIA
}

\author{
Andi Kustanto ${ }^{1}$ \\ 1. Fakultas Ekonomi dan Bisnis, Universitas Sultan Ageng Tirtayasa \\ Email: andikustanto@outlook.com
}

\begin{abstract}
Population growth and urban development continue to increase at an unprecedented rate and create pressure on the quality of clean water. Previous empirical studies have shown that uncontrolled population growth has a negative and significant impact on the quality of clean water. In the case of Indonesia, the population growth trend has decreased every year, but not followed by an index of water quality that should have increased. This study examines population growth in the water quality index in 33 provinces in Indonesia during 2013-2017 using the panel method of fixed-effect models. This study found that population growth has a negative and significant effect on the water quality index in Indonesia. Every 1000 population increase will reduce the water quality index by 0.04 (ceteris paribus), which indicates that there is a need for control of the population growth rate to be more aware of the preservation of a sustainable environment.
\end{abstract}

Keywords: Population Growth, Water Quality Index, Environment

JEL Classification: Q56, Q25, Q50

\section{PENDAHULUAN}

Pertumbuhan penduduk yang terjadi setiap tahun terus mengalami peningkatan yang berdampak pada kebutuhan air bersih semakin tinggi. Pemenuhan kebutuhan pangan dan aktivitas sehari-hari erat kaitannya dengan air bersih sebagai sumber kehidupan dan penentu bagi kualitas hidup serta kesejahteraan. Dalam studi Hatmoko et al. (2012) yang dikutip oleh Asian Development Bank (2016) memaparkan bahwa ketersediaan air permukaan di Indonesia sebesar $3.906 .476 \mathrm{~m}^{3}$ per tahun dengan persentase tertinggi di Pulau Kalimantan 34\%, Pulau Papua $27 \%$, Pulau Sumatera 22\%, Pulau Sulawesi 8\%, Pulau Maluku 5\%, Pulau Jawa $4 \%$ dan Pulau Bali dan Nusa Tenggara $1 \%$.

Kebutuhan air pada masyarakat pada tingkat internasional secara normal per orang sekitar 20 liter per hari untuk konsumsi dan kegiatan lainnya (Fogden \& Wood, 2009). Krisis air bersih telah menjadi isu global beberapa tahun terakhir. Merujuk pada laporan United Nations Development Pro- gramme (2004) dan World Water Assessment Programme (2006) mengatakan bahwa krisis air global terjadi tidak hanya persediaan air bersih yang terus berkurang, tetapi juga menunjukkan kegagalan pemerintah dalam mengelola keberlajutan lingkungan hidup. Untuk itu, eksistensi dan pengelolaan air bersih menjadi suatu hal yang mutlak diupayakan, baik persediaan dan distribusinya yang berkelanjutan.

Di Indonesia, berdasarkan data Badan Pusat Statistik menunjukkan bahwa rumah tangga yang mempunyai akses terhadap air minum layak pada tahun 2013 sebesar $67,73 \%$ dan pada tahun 2017 mengalami kenaikan menjadi sebesar 73,68\%. Untuk itu dalam upaya mewujudkan Indonesia yang sejahtera dalam akses air minum layak, pemerintah telah mengimplementasikan program 100-0-100, yang diharapkan pada 2019 masyakarakat di Indonesia memiliki porsi $100 \%$ akses terhadap air minum layak, 0 pemukiman kumuh dan $100 \%$ akses terhadap sanitasi sesuai arahan Rencana Pembangunan Jangka Menengah Nasional III 
(RPJMN III). Untuk mendukung terwujudnya program 100-0-100 tersebut dibutuhkan kualitas lingkungan hidup yang baik.

Kualitas lingkungan hidup telah dikembangkan sejak 2009 oleh Kementerian Lingkungan Hidup dengan membuat Indeks Kualitas Lingkungan Hidup (IKLH) pada tingkat nasional dan provinsi di Indonesia sebagai acuan semua pihak dalam mengukur kinerja pengelolaan dan perlindungan lingkungan hidup, yang terdiri dari tiga komponen penilaian, yaitu: Indeks Kualitas Air (IKA); Indeks Kualitas Udara (IKU); Indeks Kualitas Tutupan Lahan (IKTL). Indeks Kualitas Lingkungan Hidup (IKLH) beserta tiga komponen penghimpunnya dihitung dari 0-100. Semakin rendah dari 100, semakin besar upaya perlindungan yang harus dilakukan oleh pemerintah pusat dan daerah dalam melestarikan keberlanjutan lingkungan hidup.

Laporan Kementerian Lingkungan Hidup dan Kehutanan menunjukkan bahwa IKLH 2016 sebesar 65,73 dan pada tahun 2017 sebesar 66,47 yang mengalami kenaikan sebesar 0,73. Peningkatan IKLH nasional terjadi karena kontribusi dari IKU sebesar 221,1\%, IKA sebesar $69,5 \%$ dan IKTL sebesar $51,6 \%$. Pada tahun 2017, nilai IKA sebesar $58,68 \%$ dan provinsi yang memberikan kontribusi penurunan IKA paling tinggi adalah Provinsi Banten sebesar $44,02 \%$, yang menandakan bah- wa telah terjadi permasalahan air baik dari kuantitas dan kualitasnya.

Penurunan kualitas air bersih di Indonesia yang paling dominan diakibatkan oleh bakteri fercal coliform dan total coliform, berasal dari kotoran manusia dan hewan yang terdapat bakteri panthogen berupa shigella sp., escherihia coli, vibrio cholorae, campylobacter jejuni dan salmonella. Fenomena ini mengindikasikan bahwa pertumbuhan penduduk telah berkontribusi negatif terhadap kualitas lingkungan hidup, khususnya air bersih.

Chu \& Yu (2002) dan Kemp (2004) mengatakan bahwa pertumbuhan penduduk yang tinggi disuatu negara telah menyebabkan terjadinya penurunan kualitas lingkungan melalui banyaknya pembangunan, seperti pertanian dalam skala besar, perpindahan penduduk ke kota besar dan industrialisasi yang pengelolaan limbahnya tidak sesuai standar operasional. Pertumbuhan penduduk yang didukung dengan gaya hidup konsumtif serta perkembangan teknologi yang semakin maju telah memproduksi limbah berbahaya dan beracun, yang berakibat pada kerusakan lingkungan. Hal di atas didukung oleh studi empiris yang telah dilakukan oleh Duh, Shandas, Chang, \& George (2008); Ito (2005); Liyanage \& Yamada (2017); Maizunati \& Arifin (2017) bahwa pertumbuhan penduduk yang tinggi berpengaruh negatif dan signifikan terhadap kualitas air bersih.

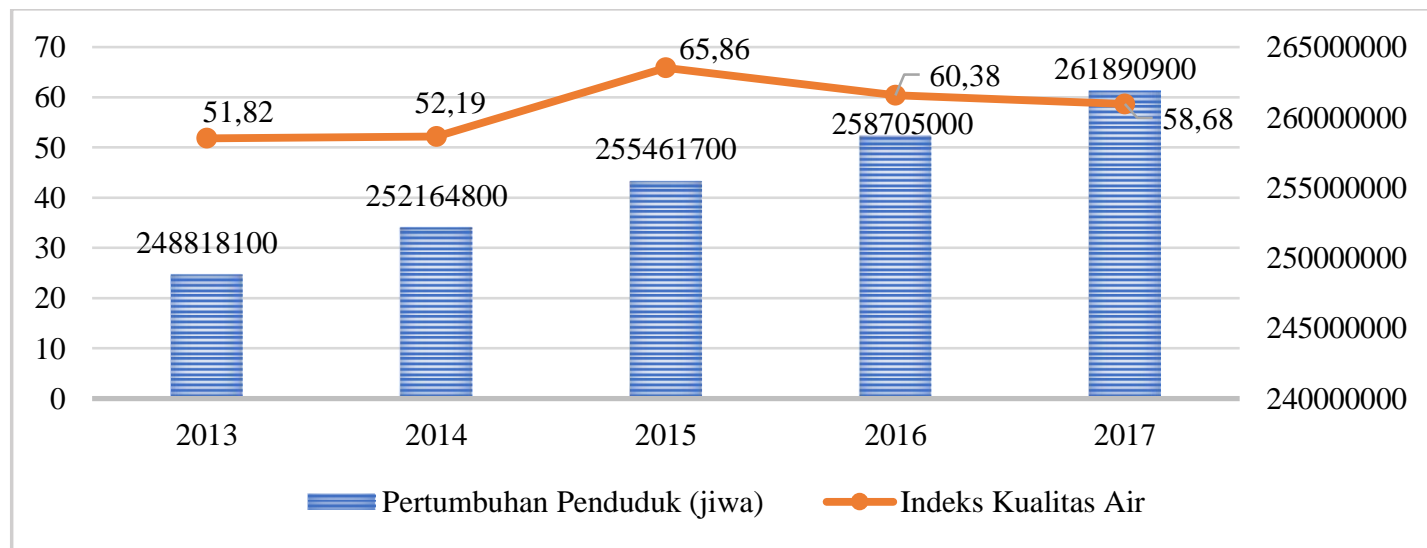

Gambar 1 Pertumbuhan Penduduk (jiwa) dan Indeks Kualitas Air di Indonesia Tahun 2013-2017 Sumber: BPS, KLHK, Berbagai Tahun, Data Diolah 
Berdasarkan data di atas menunjukkan bahwa pada tahun 2013 diketahui bahwa jumlah penduduk Indonesia sejumlah 248.818.100 jiwa dan pada tahun 2017 mengalami peningkatan sebesar $1,23 \%$ menjadi 261.890 .900 jiwa. Sedangkan skor indeks kualitas air paling rendah terjadi pada tahun 2016 $(60,38)$ dan pada tahun $2017(58,68)$. Hal ini menunjukkan bahwa pertumbuhan penduduk yang tinggi berkontribusi negatif terhadap kualitas lingkungan hidup, terutama kualitas air bersih di Indonesia. Fenomena ini menjadi bahasan menarik untuk dilakukan studi empiris terkait dengan pengaruh pertumbuhan penduduk terhadap kualitas air di Indonesia.

\section{TINJAUAN PUSTAKA DAN HI- POTESIS}

Indeks kualitas air adalah salah satu komponen pembentuk dari indeks kualitas lingkungan hidup yang disusun oleh Kemeterian Lingkungan Hidup dan Kehutanan. Indeks kualitas air diperlukan untuk melihat seberapa baik kualitas air yang dikonsumsi masyarakat baik untuk kebutuhan sehari-hari atau kegiatan lainnya. Ratnaningsih et al. (2018) mengatakan bahwa indeks kualitas air memberikan nilai tunggal terhadap kualitas yang diperoleh dari integrasi beberapa parameter penyusunnya pada waktu dan lokasi tertentu. Metode untuk menghitung indeks kualitas air menggunakan indeks pencemaran air sungai (PIj). Rumus untuk menghitung indeks pencemaran air sungai adalah sebagai berikut:

$$
\mathrm{PI}_{\mathrm{j}}=\sqrt{\frac{\left(\frac{c_{i}}{L_{i j}}\right)^{2}+\left(\frac{c_{i}}{L_{i j}}\right)_{R}^{2}}{2}}
$$

Di mana, PIj adalah indeks pencemaran air sungai pertuntukan $(j)$, yang merupakan fungsi dari $\mathrm{Ci} / \mathrm{LiJ}$. Ci menyatakan konsentrasi parameter kualitas air ke $i$ dan Lij menyatakan kon- sentrasi kualitas air $I$ yang dicantumkan dalam baku mutu air $j$. Dalam hal ini, peruntukan yang digunakan adalah klasifikasi baku muti air kelas I berdasarkan Peraturan Pemerintah Nomor 82 Tahun 2001 Tentang Pengelolaan Kualitas Air dan Pengendalian Pencemaran Air. Indeks pencemaran air sungai berdasarkan nilai PIj adalah sebagai berikut:

1) Indek kualitas air $=100$ untuk $\mathrm{PIj}$ $\leq 1$

2) Indeks kualitas air $=80$, untuk PIj $\geq 1$

3) Indeks kualitas air $=60$, untuk $\mathrm{PIj}$ $\geq 4,67$

4) Indeks kualitas air $=40$, untuk PIj $\geq 6,32$

5) Indeks kualitas air $=20$, untuk PIj $\geq 6,88$

Studi empiris tentang analisis pengaruh pertumbuhan penduduk terhadap kualitas air bersih telah banyak dilakukan, yaitu oleh Ito (2005) dalam studinya menemukan bahwa ukuran dan pertumbuhan penduduk berkontribusi negatif terhadap kualitas air bersih di kota-kota besar di China. Hal ini menunjukkan bahwa sistem pengelolaan limbah rumah tangga dan industri berbahaya dan beracun di kota-kota besar di China telah gagal dalam menyediakan kapasitas dan mengakomodasi ukuran penduduk dan pertumbuhan penduduk di China yang terus mengalami peningkatan setiap tahunnya. Studi yang dilakukan Duh et al. (2008) menemukan bahwa perpindahan penduduk dari desa ke kota telah berpengaruh negatif terhadap kualitas lingkungan hidup di kota-kota besar di dunia. Semakin bertambahnya penduduk dari desa ke kota akan menyebabkan bertambahnya bangunan perumahan, sehingga mengurangi daerah terbuka hijau, bertambahnya volume sampah rumah tangga, pencemaran air dan udara.

Liyanage dan Yamada (2017) melakukan studi tekait pertumbuhan penduduk terhadap kualitas lingkungan 
hidup di Sri Lanka, yang menunjukkan bahwa ada jarak yang harus dijaga antara daerah pada penduduk dengan daerah lainnya sekitar 2.375 meter $\mathrm{km}^{2}$ untuk menjaga agar kualitas air tanah yang bisa dikonsumsi oleh masyarakat berstatus layak dikonsumsi untuk keperluan rumah tangga dan lainnya. Selain itu, pemukiman penduduk di sekitar Daerah Aliran Sungai (DAS) harus dijaga jaraknya sekitar 2.672 meter agar kualitas air terjaga untuk keberlanjutan hidup ekosistem dan organisme air yang hidup di sungai. Studi yang dilakukan Maizunati \& Arifin (2017) yang mengambil studi kasus 33 provinsi di Indonesia menemukan bahwa perubahan jumlah penduduk telah berdampak negatif dan signifikan terhadap kualitas air. Pertumbuhan penduduk 1.000 jiwa akan berdampak pada penurunan indeks kualitas air sebesar 1,13 poin (ceteris paribus). Lebih lanjut Maizunati \& Arifin (2017) menyarankan bahwa kontrol terhadap pertumbuhan penduduk menjadi prioritas utama untuk menjaga kualitas lingkungan hidup yang terus berkelanjutan.

\section{METODE PENELITIAN}

Studi ini menggunakan metode kuantitatif dengan alat analisis ekonometrika data panel. Data panel adalah kombinasi data time series dan crosssection (Gujarati \& Porter, 2009). Dalam studi ini, data yang digunakan terdiri dari 33 provinsi di Indonesia selama 5 tahun dari 2013-2017 yang datanya bersumber dari Badan Pusat Statistik. Model yang digunakan dalam studi ini mengadopsi model studi Maizunati $\&$ Arifin (2017) dengan modifikasi sebagai berikut:

$$
\begin{aligned}
\mathrm{IKA}_{\mathrm{it}}= & \beta_{0}+\beta_{1} \mathrm{PDDK}+\beta_{2} \mathrm{PAM}+ \\
& \beta_{3} \mathrm{PDRBPK}+\beta_{4} \mathrm{AIR}+\beta_{5} \mathrm{IMK} \\
& +\beta_{6} \mathrm{INV}+\varepsilon \mathrm{it} \quad(2)
\end{aligned}
$$

Dari persamaan di atas dapat dijelaskan masing-masing dari operasional variabel adalah sebagai berikut:

$$
\begin{aligned}
& \text { IKA }=\text { Indeks Kualitas Air } \\
& \text { PDDK = Jumlah Penduduk } \\
& \text { PAM = Jumlah Air Bersih yang Di- } \\
& \text { salurkan Perusahaan Air } \\
& \text { Bersih } \\
& \mathrm{PDRBPK}=\mathrm{PDRB} \text { per kapita ADHK } \\
& 2010 \\
& \text { AIR = Persantase Rumah Tangga } \\
& \text { yang Memiliki Akses Sani- } \\
& \text { tasi Layak } \\
& \text { IKM = Jumlah Pekerja di Industri } \\
& \text { Kecil Menengah } \\
& \text { INV = Realisasi PMDN dan PMA } \\
& \mathrm{B} 0=\text { Intersep } \\
& \text { B1 s.d } \beta 6=\text { Koefisien Regresi } \\
& i=\text { Jumlah unit cross-section } \\
& \text { terdiri dari } 33 \text { Provinsi di } \\
& \text { Indonesia } \\
& t=\text { Periode Waktu Tahun } \\
& \text { 2013-2017 } \\
& \text { = Error Term }
\end{aligned}
$$

Penggunaan transformasi logaritma natural akan membuat model yang hubungannya tidak linear dapat digunakan dalam model linear. Selain itu, transformasi logaritma natural dapat merubah data yang pada awalnya berdistribusi condong atau tidak berdistribusi normal menjadi atau mendekati distribusi normal sehingga menghasilkan model terbaik yang terbebas dari multikolinearitas, heterokedastisitas dan autokorelasi (Gujarati \& Porter, 2009).

\section{ANALISIS DATA DAN PEMBA- HASAN}

Penyediaan layanan air bersih di Indonesia telah dijamin dalam Pasal 33 Undang-Undang Dasar 1945 ayat (3) yang berbunyi "bumi dan air dan kekayaan alam yang terkandung di dalamnya dikuasai oleh negara dan dipergunakan untuk sebesar-besarnya kemakmuran rakyat". Kemudian diperkuat kembali oleh Undang Undang No. 23 Tahun 2014 tentang Pemerintah Daerah bahwa pemenuhan pelayanan air bersih bagi masyarakat merupakan tanggung jawab pemerintah daerah sebagai bentuk pelayanan publik yang 
mutlak dilakukan untuk kesejahteraan masyarakat.

Persentase rumah tangga dengan sumber air minum layak di Indonesia setiap tahunnya mengalamai fluktuasi dan porsi capaiannya belum optimal sampai 100\%. Data Badan Pusat Statistik menunjukkan bahwa pada level provinsi di tahun 2013, porsi rumah tangga dengan sumber air minum layak tertinggi, yaitu di Provinsi DKI Jakarta 92,49\%, Provinsi Bali 89,79\% dan Provinsi Kalimantan Timur 79,99\%. Sedangkan provinsi yang memiliki porsi rumah tangga dengan sumber air minum layak terendah terdapat pada Provinsi Bengkulu 36,82\%, Provinsi Sulawesi Barat 42,14\% dan Provinsi Papua $44,12 \%$.
Pada tahun 2017 porsi rumah tangga terhadap air minum layak tertinggi yaitu Provinsi Bali 90,85\%, Provinsi DKI Jakarta 88,93\% dan Provinsi Kepulauan Riau 83,95\%. Sedangkan provinsi yang memiliki porsi rumah tangga terhadap air minum layak terendah terdapat pada Provinsi Bengkulu 43,83\%, Provinsi Lampung 53,79\% dan Provinsi Papua 59,09\%. Pada tahun 2013 sebagai awal tahun penelitian, Provinsi DKI Jakarta menempati urutan pertama sebagai provinsi dengan akses rumah tangga terhadap air minum layak sebesar $92,49 \%$, tetapi pada tahun 2017 mengalami penurunan menjadi $88,93 \%$. Hal ini terjadi dikarenakan kondisi Sungai Ciliwung terus memburuk akibat tercemar oleh limbah rumah tangga dan industri

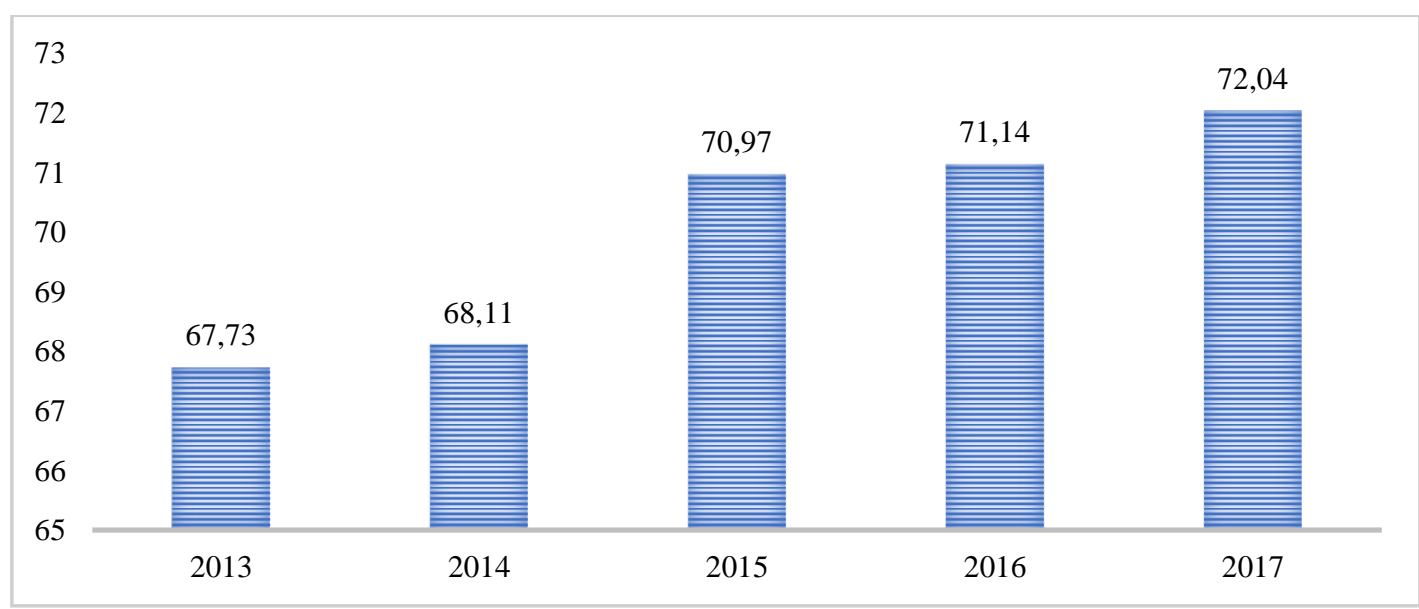

Gambar 2 Rumah Tangga dengan Sumber Air Minum Layak di Indonesia Tahun 2013-2017 (persen) Sumber: Badan Pusat Statistik, Berbagai Tahun, Data Diolah

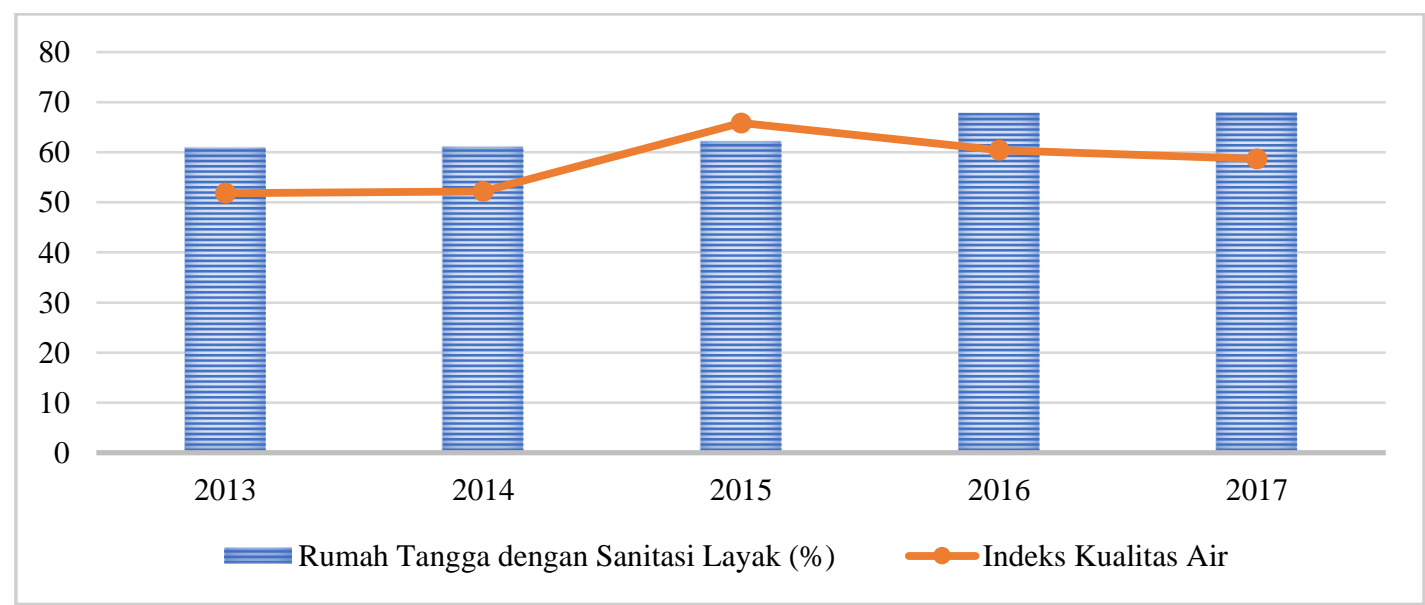

Gambar 3 Rumah Tangga dengan Akses Sanitasi Layak (persen) dan Indeks Kualitas Air di Indonesia Tahun 2013-2017

Sumber: BPS, KLHK, Berbagai Tahun, Data Diolah 
Upaya pemerintah pusat dan daerah dalam upaya kelestraian lingkungan hidup, khususnya pada kualitas air bersih terus menunjukkan peningkatan. Ditandai dengan akses rumah tangga dengan sanitasi layak terus meningkat porsinya, tetapi tidak diikuti dengan indeks kualitas air yang setiap tahun mengalami fluktuasi. Berdasarkan data dari Pusat Data Statistik bahwa pada tahun 2013 provinsi yang memiliki akses rumah tangga dengan sanitasi layak tertinggi terdapat pada Provinsi DKI Jakarta 86,60\%, Provinsi Bali 85,15\% dan Provinsi DI Yogyakarta 82,03\%. Sedangkan provinsi yang memiliki akses terendah pada rumah tangga dengan sanitasi layak terdapat pada Provinsi Nusa Tenggara Timur 24,91\%, Provinsi Papua 25,37\% dan Provinsi Bengkulu 35,06\%.

Pada tahun 2017, provinsi yang memilik porsi tertinggi pada rumah tangga dengan akses sanitasi layak yaitu Provinsi DKI Jakarta 89,40\%, Provinsi Bali $90,51 \%$ dan Provinsi DI Yogyakarta 89,40\%. Dan pada tahun 2013 provinsi yang memiliki akses rumah tangga terhadap sanitasi layak terendah terdapat pada Provinsi Papua 33,06\%, Provinsi Bengkulu 42,71\% dan Provinsi Nusa Tengga Timur 45,31\%. Ini menunjukkan bahwa belum ada satupun provinsi di Indonesia yang memiliki akses rumah tangga dengan sanitasi layak $100 \%$.

Tabel 1 IKLH, IKA dan Proyeksi

Pertumbuhan Penduduk (persen) di Indonesia Tahun 2013-2017

\begin{tabular}{cccc}
\hline Tahun & IKLH & IKA & $\begin{array}{c}\text { Proyeksi } \\
\text { Pertumbuhan } \\
\text { Penduduk (\%) }\end{array}$ \\
\hline \hline 2013 & 63.13 & 51.82 & 1,38 \\
\hline 2014 & 63.42 & 52.19 & 1,35 \\
\hline 2015 & 68.23 & 65.86 & 1,31 \\
\hline 2016 & 65.73 & 60.38 & 1,27 \\
\hline 2017 & 66.46 & 58.68 & 1,23 \\
\hline \hline
\end{tabular}

Sumber: BPS, KLHK, Berbagai Tahun Data Diolah
Secara konseptual, nilai Indeks Kualitas Lingkungan Hidup (IKLH) bersifat komparatif, artinya nilai satu provinsi relatif terhadap provinsi lain dan setiap provinsi memberi kontribusi terhadap nasional secara proporsional berdasarkan jumlah penduduk dan luas wilayahnya terhadap total penduduk dan luas wilayah Indonesia. Data di atas menunjukkan bahwa nilai IKLH yang setiap tahunnya mengalami kenaikan nilai IKA berkontribusi relatif kecil. Karena terjadi perubahan setiap tahun diakibatkan dari pertumbuhan penduduk yang terus meningkat.

\section{Hasil Uji Spesifikasi Model Uji Hausman}

Uji Hausman adalah pengujian statistik sebagai dasar pertimbangan memilih model terbaik apakah menggunakan fixed effect model atau random effect model (Gujarati \& Porter, 2009).

Tabel 2 Hasil Uji Hausman

\begin{tabular}{cccc}
\hline Test & Chi-Sq. & Chi- & Prob. \\
Summary & Statistic & Sq. d.f. & \\
\hline \hline $\begin{array}{c}\text { Cross-section } \\
\text { random }\end{array}$ & 13.571783 & 6 & 0.0348 \\
\hline \hline
\end{tabular}

Sumber: E-views 10, data diolah

Berdasarkan tabel 2 di atas menunjukkan bahwa nilai prob. Cross-section random $<\alpha(0.05)$ atau $0.0000<0.05$, maka model terbaik yang digunakan adalah fixed effect model.

\section{Hasil Analisis Regresi Data Panel}

Model dalam studi ini yang akan diestimasi adalah jumlah penduduk, jumlah air bersih yang disalurkan perusahaan air bersih, PDRB per kapita ADHK 2010, jumlah pekerja di industri kecil menengah, realisasi PMDN dan PMA terhadap indeks kualitas air pada 33 provinsi di Indonesia selama tahun 2013-2017. Studi ini menggunakan n dengan jumlah 279 sampel, sehingga $n$ $\geq 30$ data dianggap berdistribusi normal. Semakin besar nilai $n$, maka aproksimasi cental limit theorem akan semakin akurat atau semakin mendekati 
distribusi normal (Gujarati \& Porter, 2009). Hasil estimasi dalam studi ini terbebas dari masalah multikolinearitas, tidak terdapat heterokedastisitas dan tidak terjadi masalah autokorelasi.

Hasil estimasi dengan fixed effect model pada tabel 3 dapat ditulis sebagai berikut:

$$
\begin{aligned}
& \mathrm{IKA}_{\text {it }}=6.492206-0.048162+ \\
& 0.148111+0.239726+ \\
& 1.023660+1.057884- \\
& 0.000278+\varepsilon i t
\end{aligned}
$$

Secara empiris, estimasi di atas menunjukkan bahwa jumlah penduduk berdampak negatif dan signifikan terhadap indeks kualitas air dengan nilai koefisien -0.048162 dan probabilitas 0.3445 sejalan dengan studi yang dilakukan Duh et al. (2008); Ito (2005); Liyanage \& Yamada (2017); Maizunati \& Arifin (2017) mengatakan bahwa kegiatan manusia semakin kompleks dan beragam pada suatu kota akan mempengaruhi kualitas air yang disebabkan oleh limbah buangan dari rumah tangga dan kawasan industri. Selain itu, jumlah pekerja pada industri kecil dan menengah juga berpengaruh negatif terhadap indeks kualitas air. Hal ini sejalan dengan penelitian Maizunati \& Arifin (2017) yang menjelaskan bahwa pertumbuhan industri kecil dan menengah ini pada satu sisi menandakan kemajuan perekonomian yang menyerap tenaga kerja, tetapi di satu sisi yang lain berpengaruh negatif terhadap kualitas air bersih, diperlukan pantauan khusus dalam pengelolaan limbah industri sehingga pencemaran air bersih di sekitar kawasan industri dimitigasi secara optimal dengan pembuatan pengelolaan air limbah.

Studi ini menemukan pengaruh positif dan signifikan terkait jumlah air yang disalurkan perusahaan air bersih dan rumah tangga dengan akses sanitasi layak. Ini membuktikan bahwa kinerja pemerintah dalam pelestarian lingkungan hidup membuahkan hasil positif. Namun, porsi layanan air bersih di Indonesia belum sampai $100 \%$, perlu adanya peningkatan penyediaan layanan air bersih baik yang disalurkan perusahaan air bersih dan peningkatan rumah tangga berpenghasilan rendah di daerah tertinggal, terluar dan terdepan. Kedua hal di atas sangat perlu dioptimalkan untuk peningkatan kesejahteraan dan kualitas hidup masyarakat. Selain itu, variabel lain yang berpengaruh positif dan signifikan adalah PDRB per kapita. Ini menunjukkan bahwa dengan adanya peningkatan pendapatan, kesadaran masyarakat akan pentingnya investasi pada layanan air bersih terus menjadi kebutuhan utama dalam kebutuhan sehari-hari. Hutton (2013) menjelaskan bahwa dengan adanya tambahan investasi pada layanan air bersih dan sanitasi layak sebesar \$1 akan menghasilkan return of investment sebesar \$4 serta memberikan dampak ekonomi jangka panjang yang positif agar terhindar dari penyakit yang diakibatkan pencemaran air.

Tabel 3 Hasil Estimasi dengan Fixed Effect Model

\begin{tabular}{lccc}
\hline \multicolumn{1}{c}{ Variable } & Coefficient & t-Statistic & Prob. \\
\hline \hline $\mathrm{C}$ & 6.492206 & 2.455271 & 0.0155 \\
\hline $\ln P D D K$ & -0.048162 & -1.790194 & 0.3445 \\
\hline $\ln$ PAM & 0.148111 & 2.487821 & 0.0000 \\
\hline $\operatorname{lnPDRBPK}$ & 0.239726 & 12.38991 & 0.0040 \\
\hline $\ln$ AIR & 1.023660 & 7.476704 & 0.0001 \\
\hline $\operatorname{lnIMK}$ & 1.057884 & 7.823421 & 0.1095 \\
\hline $\ln I N V$ & -0.000278 & -1.296223 & 0.0475 \\
\hline R-squared & & 0.761963 & \\
\hline F-Statistics & & 10.45546 & \\
\hline Prob. (F-Statistic) & & 0.000000 & \\
\hline \hline
\end{tabular}

Sumber: E-views 10, data diolah 
Temuan lain dalam studi ini adalah variabel investasi dari realisasi proyek PMDN dan PMA berpengaruh positif dan tidak seginifikan terhadap kualitas air di Indonesia. Hal ini menyiratkan bahwa dengan banyak proyek pembangunan di provinsi-provinsi di Indonesia akan menumbuhkan efek pengganda bagi perekonomian daerah, karena dengan adanya investasi akan mendorong peningkatan sisi produksi dan sisi konsumsi. Sisi produksi dari investasi akan memberikan kemudahan akses terhadap faktor-faktor produksi, salah satunya sumber daya manusia. Sedangkan dari sisi konsumsi, investasi secara otomatis akan meningkatkan kegiatan ekonomi domestik. Tetapi dari peningkatan proyek-proyek investasi tersebut, harus terus dalam pengawasan dan pengendalian air bersih dengan peraturan perundang-undangan, izin pembuangan limbah cair dan penerapan teknologi online monitoring secara real time di kawasan industri.

\section{KESIMPULAN, IMPLIKASI, SARAN, DAN BATASAN}

Dari hasil studi empiris yang telah dilakukan, perubahan pertumbuhan penduduk telah berpengaruh negatif dan signifikan terhadap indeks kualitas air di Indonesia, terlepas dari jenis dan macam pencemaran air yang terjadi baik skala regional maupun nasional. Berdasarkan tabel 1 di atas yang menunjukkan bahwa proyeksi pertumbuhan penduduk di Indonesia memiliki tren yang menurun setiap tahunnya, tetapi proyeksi pertumbuhan penduduk yang dilakukan Badan Pusat Statistik pada tahun 2035 akan mencapai angka 300 jiwa, maka diperlukan kontrol terhadap penduduk untuk meningkatkan kesejahteraan dan kesadaran terhadap kualitas lingkungan hidup yang berkelanjutan.

Keterbatasan dalam studi ini, menggunakan data agregat level provinsi dengan rentang waktu yang sing- kat dari 2013-2017, menyebabkan analisis yang dilakukan menggunakan data panel statis dan koefisien pada jumlah penduduk terhadap indeks kualitas air hanya sebesar 0,04. Diharapkan pada studi lanjutan, agar menggunakan data pada level individu atau level kabupaten kota dengan menggunakan data mikro dan model penelitian yang terus disempurnakan untuk menghasilkan analisis yang lebih mendalam tentang akses air bersih di Indonesia.

\section{DAFTAR PUSTAKA}

Asian Development Bank. (2016). Indonesia Country Water Assessment. Mandaluyong City, Philippines: Asian Development Bank.

Chu, C. Y. C., \& Yu, R. R. (2002). Population Dynamics and the Decline in Biodiversity: A Survey of the Literature. Population and Development Review, 28, 126143. Retrieved from https://www.jstor.org/stable/3115 270

Duh, J. Der, Shandas, V., Chang, H., \& George, L. A. (2008). Rates of Urbanisation and The Resiliency of Air and Water Quality. Science of the Total Environment, 400(13), 238-256. https://doi.org/10.1016/j.scitoten v.2008.05.002

Fogden, J., \& Wood, G. (2009). Access to Safe Drinking Water and Its Impact on Global Economic Growth. Bothell, WA, USA: HaloSource Inc.

Gujarati, D. N., \& Porter, D. C. (2009). Basic Econometrics (Fifth Edit). New York: McGraw-Hill Irwin.

Hutton, G. (2013). Global Costs and Benefits of Drinking-Water Supply and Sanitation Interventions to Reach the MDG Target and Universal Coverage. Journal of Water and Health, 
11(1),

$1-12$.

https://doi.org/WHO/HSE/WSH/ 12.01

Ito, C. (2005). Urbanization and Water

Pollution in China. APSEG Discussion Papers, 05-13(13), 123.

Kemp, D. D. (2004). Exploring Environmental Issues: An Integrated Approach (1st ed.). London and New York: Routledge.

Liyanage, C. P., \& Yamada, K. (2017). Impact of Population Growth on The Water Quality of Natural Water Bodies. Sustainability (Switzerland), 9(8), 1-14. https://doi.org/10.3390/su908140 5

Maizunati, N. A., \& Arifin, M. Z. (2017). Pengaruh Perubahan Jumlah Penduduk Terhadap Kualitas Air di Indonesia. Jurnal Litbang Provinsi Jawa Tengah, 15(2), 207-215. https://doi.org/https://doi.org/10. 36762/litbangjateng.v15i2.417

Peraturan Pemerintah Nomor 82
Tahun 2001 Tentang Pengelolaan Kualitas Air dan Pengendalian Pencemaran Air.

Ratnaningsih, D. R., Puji Lestari, R., Nazir, E., Diah Pitalokasari, O., \& Fauzi, R. (2018). Pengembangan Indeks Kualitas Air Sebagai Alternatif Penilaian Kualitas Air Sungai. Jurnal Ecolab, 12(2), 5361.

https://doi.org/10.20886/jklh.201 8.12.2.53-61

Undang Undang No. 23 Tahun 2014 tentang Pemerintah Daerah.

United Nations Development Programme. (2004). Water Governance for Poverty Reduction (K. Lewis, ed.). New York: United Nations Development Programme.

World Water Assessment Programme. (2006). Water: a Shared Responsibility (The United Nations World Water Development Report 2). Retrieved from http://www.unesco.org/water/ww ap 